\title{
Impact of hen treatment with bee pollen and thermal manipulation during early egg incubation period on the hatchability and embryonic development of chicks
}

\author{
A.A. Abuoghaba ${ }^{1,3}$, Y.S. Rizk ${ }^{2}$, I.I. Ismail' ${ }^{2}$ and N.B. Awadien ${ }^{2}$ \\ ${ }^{1}$ Sohag University, Faculty of Agriculture, Poultry Production Department, 82524 Sohag, Egypt \\ ${ }^{2}$ Agriculture Research Center, Animal Production Research Institute, Poultry Breeding Department, Dokki, Giza, 12618, Egypt
}

KEY WORDS: bee-collected pollen, hens, incubation temperatures, egg hatchability, haematological parameters, chicks

Received: 12 December 2017

Revised: $\quad 27$ March 2018

Accepted: 12 December 2018

${ }^{3}$ Corresponding author:

e-mail: abuoghaba@yahoo.com

\begin{abstract}
The aim of the experiment was to evaluate the effect of different incubation temperatures on hatchability, embryonic development and physiological responses of chicks produced from hens treated with bee pollen (BP). In total, 600 Sinai hatching eggs were equally collected from hens treated with $0,500,1000$ and $1500 \mathrm{mg} \mathrm{BP} / \mathrm{kg}$ diet (four dietary groups) and then divided into two equal incubation groups. In the group 1 , eggs were incubated at normal temperature $\left(37.5^{\circ} \mathrm{C}\right)$ up to the day 18 , while those in the group 2 were incubated at the same conditions except 3 days (days 6,7 and 8) during which eggs were exposed to chronic temperature $\left(40^{\circ} \mathrm{C}\right)$ for $3 \mathrm{~h}$ a day. The highest relative water loss (RWL) and embryonic mortality (EM) were observed in the chronic group $(P \leq 0.05)$ as compared with control. The hatchability percentages for set (HSE) and fertile eggs (HFE) in the chronic group were significantly $(P \leq 0.05)$ decreased, while dead after piping (DAP) was insignificantly increased in comparison with control. Blood heterophils: lymphocytes $(\mathrm{H}: \mathrm{L})$ ratio, and triiodothyronine (T3) and thyroxin (T4) levels were significantly $(P \leq 0.05)$ influenced by incubation temperatures. Egg weight (EW8d) (at dose $1000 \mathrm{mg} \mathrm{BP} / \mathrm{kg}$ ), HSE, HFE for eggs produced from hens treated with $\mathrm{BP}$ were significantly $(P \leq 0.05)$ higher, while the percentages of DAP (for doses 500 and $1000 \mathrm{mg} \mathrm{BP} / \mathrm{kg}$ ) and EM were significantly $(P \leq 0.05)$ lower in comparison with control. T3 plasma content (for doses 500 and $1000 \mathrm{mg} \mathrm{BP} / \mathrm{kg})$ for chicks from BP-treated hens was significantly $(P \leq 0.05)$ higher, while $\mathrm{H}: \mathrm{L}$ ratio (for doses 500 and $1000 \mathrm{mg} \mathrm{BP} / \mathrm{kg}$ ) was significantly $(P \leq 0.05)$ lower as compared with control. The obtained results showed that eggs exposure to higher temperature in early incubation period negatively influenced hatchability, and chick quality traits and haematological parameters; however the addition of BP into hen diet can improve the examined parameters and so reduce the adverse effects of high incubation temperature.
\end{abstract}

\section{Introduction}

During incubation, the development of chick embryos is not only affected by genetic makeup but also many micro-environmental factors can influence dynamic processes in hatching eggs (Willemsen et al., 2010). In commercial farming the opti- mum incubation temperature for chick ranges from $37{ }^{\circ} \mathrm{C}$ to $38^{\circ} \mathrm{C}$ (Hulet et al., 2007). The eggshell temperature, depending on exposure duration, temperature degree and embryonic age, is one of the main factors affecting embryonic development as well as chick quality traits (Wilson, 1991; Narinç et al., 2016). Therefore, exposure of hatching eggs 
to high temperature during early incubation adversely affect the hatchability, embryo performance, and blood biochemical changes (Molenaar et al., 2011). The effects of different incubation temperatures and the duration of exposure on the hatchability and chick quality were described previously (Leksrisompong et al., 2007). In the last decades, several attempts were made to reduce the harmful effects of high incubation temperature on chick embryos (Sgavioli et al., 2015; Abuoghaba, 2017). Abuoghaba (2017), for instance, sprayed hatching eggs with ascorbic acid after exposure to high temperature during the incubation period to reduce the heat stress of the chick embryos. There were also injections of some anti-heat stress substances to hatching eggs during incubation or in ovo injections of bee pollen (BP) in order to ameliorate and reduce the adverse effect of heat stress (Coşkun et al., 2014).

Bee pollen is a rich source of: carbohydrates $13-55 \%$, proteins $10-40 \%$, lipids $1-20 \%$, flavonoids $0.004-3.0 \%$, minerals $0.5-3.0 \%$, vitamins $0.02-0.1 \%$ and water $3-8 \%$ as well as other compounds such as antibiotic substances (Carpes et al., 2007). Therefore, $\mathrm{BP}$ can be used in the poultry nutrition to improve the immunological responses and haematological parameters (Song et al., 2005). In poultry BP also promotes performance, enhances immunological functions as well as protects intestinal tract (Liu et al., 2010).

There were several attempts to include BP (as a natural product) to poultry diet as an antibiotic substitute and to improve animal productive and reproductive performances (Farag and El-Rayes, 2016). However, injection of such a substance directly to the hatching eggs being under incubation requires special technique and specialized machines and so it is extremely difficult for small breeders and farmers (Abuoghaba, 2017). Due to this fact, it was suggested that adding BP to laying hen diet could reduce thermal stress in embryos during incubation.

Therefore, this experiment was designed to investigate the effects of incubation temperatures of hatching eggs produced from Sinai hens treated with 500,1000 and $1500 \mathrm{mg} \mathrm{BP} / \mathrm{kg}$ diet on hatchability, embryonic development and some haematological and physiological parameters of chicks.

\section{Material and methods}

This experiment was approved by the Experimental Animal Ethics Committee of Animal Production Research Institute, Agricultural Research Center, Egypt (the research committee approval date 12/6/2016).

\section{Experimental design and eggs treatment}

Six hundred hatching eggs were equally collected form Sinai hens at 38 week of age, i.e. after 12 weeks from the treatment with $0,500,1000$ and $1500 \mathrm{mg} \mathrm{BP} / \mathrm{kg}$ diet throughout the experiment. All hens were fed a basal diet containing $16.5 \%$ crude protein, $3.5 \%$ crude fibre, $3.0 \%$ ether extract and $2700 \mathrm{kcal} / \mathrm{kg}$ metabolizable energy. Hens were divided into 4 dietary groups: hens from the control group were fed basal diet, while those from groups 2, 3 and 4 were fed the same basal diet supplemented with bee pollen at doses 500, 1000 and $1500 \mathrm{mg} / \mathrm{kg}$ diet, respectively. All hens were housed in individual pens $(150 \mathrm{~cm}$ width $\times 200 \mathrm{~cm}$ length $)$ equipped with feeders and automatic nipples under normal climatic conditions $\left(20-22{ }^{\circ} \mathrm{C}\right.$ and $60-65 \%$ $\mathrm{RH})$, and daily subjected to $16 \mathrm{~h}$ of continuous light.

From each group, 150 eggs were collected and then equally divided into two incubation groups as follows: in the first group eggs were incubated at $37.5{ }^{\circ} \mathrm{C}$ and with $55 \%$ relative humidity ( $\mathrm{RH}$ ) up to day 18 , while those from the second group were incubated at the same incubation temperature except 3 days (days 6,7 , and 8), during which eggs were exposed to $40.0{ }^{\circ} \mathrm{C}$ and $55 \% \mathrm{RH}$ for $3 \mathrm{~h}$ a day in the separate hatchery. In the last 3 days of the incubation, all eggs from both incubation groups were subjected to $37.0{ }^{\circ} \mathrm{C}$ and $65 \% \mathrm{RH}$ with $\mathrm{CO}_{2}$ concentration in the normal range between 0.20 and $0.30 \%$. The incubation temperature was automatically adjusted and automatically turned through $90^{\circ}$ tilt angle every $2 \mathrm{~h}$. All eggs were placed horizontally in the automatic incubator after the cleaning eggshell surface with $75 \%$ ethanol.

\section{Measured traits}

All hatching eggs were numbered and weighed (egg weight, EW) prior placing it in the incubator. Egg relative water loss (RWL; \%) was measured from the equation: [(EW at day $1-\mathrm{EW}$ at day 8$) /$ $(E W$ at day 1)] $\times 100$. Hatchability of set eggs (HSE, \%) was estimated as (number of healthy chicks) $/$ (number of total eggs) $\times 100$, while the hatchability of fertile eggs (HFE, \%) was measured by applying the following equation: (number of healthy chicks) / (number of fertile eggs) $\times 100$. Percentage of dead after piping (DAP, \%) was determined as follows: (number of chicks piped and dead) $/$ (number of total eggs) $\times 100$, while embryonic mortality (EM, \%) was calculated as follows: (number of dead chick embryos) / (number of total eggs) $\times 100$. 


\section{Chick quality traits and internal organ percentages}

Seventy two dry Sinai chicks $(4$ hens from dietary groups $\times 2$ egg incubation groups $\times 3$ replicates $\times 3$ chicks) were randomly taken to determine chick weight $(\mathrm{ChW})$, length $(\mathrm{ChL})$ and cloacal temperature. Newly hatched chicks were weighed to determine the weight of chicks by using a balance with $\pm 0.1 \mathrm{~g}$ precision. Relative chick weight (RChW) was calculated as follows: (chick weight) / (egg weight $) \times 100$. Chick length $(\mathrm{cm})$ was measured from the beak tip up to the middle toe tip by placing the chick face down on a flat surface and straightening the right leg (Hill, 2001). The cloacal temperature $\left({ }^{\circ} \mathrm{C}\right)$ of newly hatched chicks was evaluated by inserting the digital thermometer $\left( \pm 0.1^{\circ} \mathrm{C}\right.$ accuracy) into the cloaca at $1 \mathrm{~cm}$ deep. All chicks were slaughtered by cervical dislocation to measure digestive system, spleen, liver and heart weight.

\section{Blood collection}

In total, 72 blood samples ( 4 hens from dietary groups $\times 2$ egg incubation groups $\times 3$ replicates $\times$ 3 chicks), $1 \mathrm{ml}$ of blood per chick, were collected for haematological tests, including the packed cell volume (PCV) and haemoglobin $(\mathrm{Hb})$ content and were determined by using a micro-haematocrit method as well as spectrophotometrically measured using the cyanomet haemoglobin method according Schalm et al. (1975). The red blood cells count $\left(\mathrm{RBC}, \times 10^{6}\right)$ was estimated by using a haemocytometer (Schalm et al., 1975), while count of white blood cells $\left(\mathrm{WBCs}, \times 10^{3}\right.$ ) was measured by using the method according to Gross and Siegel (1983). The percentages of heterophils (H), lymphocytes (L), monocytes (M) and eosinophils (E) were measured by applying the method of Shen and Patterson (1983). Later heterophils : lymphocytes ratio $(\mathrm{H}: \mathrm{L}$ ratio) was calculated. All blood samples were centrifuged for $15 \mathrm{~min}$ at $4000 \mathrm{rpm}$ and then kept at $-18{ }^{\circ} \mathrm{C}$ until chemical analysis of thyroid hormones. The concentrations of triiodothyronine (T3) and thyroxin (T4) in the plasma were measured using radioimmuno assay (RIA) according to Darras et al. (1996).

\section{Statistical analysis}

Data were subjected to the two-way analysis of variance (ANOVA) using SAS software ver. 9.2 (SAS Institute, Cary, NC, USA). The means between from either dietary groups or egg incubation temperature groups were compared using Duncan's multiple range test (Duncan, 1955).

\section{Results and discussion}

\section{Relative water loss, hatchability and embryonic mortality}

The effects of egg incubation temperature during the early incubation period on egg water loss, hatchability, and embryonic mortality rate are summarized in Table 1. It was noted that EW and EW8-day for eggs exposed to chronic incubation temperature $\left(40.0^{\circ} \mathrm{C}\right)$ did not differ from the group exposed to normal temperature, while the RWL was significantly $(P \leq 0.05)$ increased. The increased RWL could be due to the increased evaporation of water from the eggshell as a result of high incubation temperature during exposure to heat stress. These findings are in agreement with the findings of Geng and Wang (1990), who showed that the fast moisture loss during incubation was disadvantageous and deleteriously affected the normal embryonic development. Also, these findings agree with Sgavioli et al. (2015), who found that the eggshell conductance or egg weight loss were significantly influenced by incubation temperature [higher values were recorded in the eggs incubated at high temperature $\left(39^{\circ} \mathrm{C}\right)$ than in eggs incubated at normal temperature $\left.\left(37.5^{\circ} \mathrm{C}\right)\right]$.

There were also shown significant effects $(P \leq 0.05)$ of the incubation temperature on HSE and HFE percentages which were lower for eggs in the chronic group. Embryo mortality rate was significantly higher when incubation temperature was increased. The decreased hatchability percentages for hatching eggs exposed to high incubation temperature $\left(40{ }^{\circ} \mathrm{C}\right)$ may be due to insufficient nutrients absorption rate. These findings agree with those of Lourens et al. (2005) who stated that the differences in the hatchability and chick quality from eggs exposed to high incubation temperature may be due to the differences in the nutrient use or nutrient absorption efficiency from the egg. Similarly, the results of Sgavioli et al. (2015) indicated that the decreased hatchability in the eggs incubated at the hot temperature could be an indication of increased evaporative heat loss, which negatively affected the embryonic development and consequently reduced the hatchability.

Referring to BP effect, it was shown that in comparison to control treatment the EW and EW-8d were higher in hens fed diet supplemented with $1000 \mathrm{mg} \mathrm{BP} / \mathrm{kg}$ diet, whereas HSE and HFE for eggs produced from the hens treated with BP regardless its dose were significantly higher $(P \leq 0.05)$. No effect on the RWL (\%) was stated. The increased hatchability percentages in the administered groups 
could be attributed to a high antioxidant capacity of BP, which positively influences the hatchability. The increased hatchability percentages of the treated groups may be due to the low cholesterol level in the treated egg, which is positively reflected on the hatchability. These results agree with Awad et al. (2013) who showed significantly increased hatchability percentage of set eggs in Sinai hens administered $0.5 \mathrm{~g}$ bee bread $/ \mathrm{kg}$ diet in comparison to control group.

The achieved results showed that the DAP (except of group with $1500 \mathrm{mg} \mathrm{BP} / \mathrm{kg}$ diet addition) and EM percentages in eggs produced by hens treated with BP were significantly $(P \leq 0.05)$ decreased in comparison to control ones. The increased DAP and EM percentages in the control group (untreated) may be due to increasing water loss percentage from the eggs leading to high DAP as well as EM because of dehydration. These results disagree with the findings of Aygun (2016) who found that the hatchability of fertile eggs and EM for eggs treated with distilled water and injected with 1,2 and $3 \%$ propolis water extract were not affected. Also, the findings of Abuoghaba (2017) showed that the DAP, EM were not affected by ascorbic acid treatment or the interaction between incubation temperature and ascorbic acid treatment.

All studied traits, except EW, EW-8d, and RWL, were significantly affected by the interaction between incubation temperature and BP treatment (Table 1).

\section{Chick quality traits and internal organ percentages of newly chicks at hatching}

The effects of high incubation temperature during early embryonic development on chick quality traits and some internal organ percentages at hatching are shown in Table 2. These findings indicated that the $\mathrm{ChW}(\mathrm{g}), \mathrm{RChW}(\%), \mathrm{ChL}(\mathrm{cm})$ in the chronic group were not affected as compared to the control one. These results disagree with Yahav et al. (2004), who stated that the chick BW at hatch was significantly decreased at high incubation temperature in comparison to normal temperature. They attributed the decreased chick weight to a reduction in the absorption of the yolk sac, which reduces the available nutrients for chick embryo development as well as hatch weight.

The achieved findings showed no significant differences between both groups in DSW (\%), while the spleen percentage was significantly $(P \leq 0.05)$ higher in the chronic group than in the control group. The increased spleen percentage in the chronic group may be attributed to stimulation of chick immune responses. These findings disagree with Abuoghaba (2017), who reported that the percentages of spleen were significantly lower in the broiler chicks produced from eggs exposed to chronic temperature $\left(40{ }^{\circ} \mathrm{C}\right)$ than in those produced in the normal $\left(37.5^{\circ} \mathrm{C}\right)$ temperature. The liver and heart percentages were significantly $(P \leq 0.05)$ lower in the broiler chicks produced from eggs exposed to chronic temperature $\left(40{ }^{\circ} \mathrm{C}\right)$

Table 1. Effect of egg incubation temperature and bee pollen treatment of hens on relative water loss, hatchability and embryonic mortality

\begin{tabular}{|c|c|c|c|c|c|c|c|}
\hline Indices & EW, g & EW8d, g & RWL, \% & HSE, \% & HFE, \% & DAP, $\%$ & $\mathrm{EM}, \%$ \\
\hline \multicolumn{8}{|c|}{ Effect of incubation temperature (IT) } \\
\hline chronic $\left(40^{\circ} \mathrm{C}\right)$ & 52.74 & 51.14 & $3.02^{\mathrm{a}}$ & $83.168^{b}$ & $87.56^{b}$ & 4.32 & $8.11^{\mathrm{a}}$ \\
\hline normal $\left(37.8^{\circ} \mathrm{C}\right)$ & 52.74 & 51.45 & $2.53^{b}$ & $85.692^{\mathrm{a}}$ & $88.89^{a}$ & 3.77 & $7.34^{\mathrm{b}}$ \\
\hline SEM & 0.116 & 0.158 & 0.188 & 0.780 & 0.172 & 0.22 & 0.24 \\
\hline \multicolumn{8}{|c|}{ Effect of bee pollen treatments (BP) } \\
\hline control & $52.31^{b}$ & $50.80^{b}$ & 2.89 & $80.58^{b}$ & $85.59^{c}$ & $4.83^{\mathrm{a}}$ & $9.58^{\mathrm{a}}$ \\
\hline $500 \mathrm{mg} / \mathrm{kg}$ diet & $52.67^{b}$ & $51.26^{\mathrm{ab}}$ & 2.86 & $85.13^{\mathrm{a}}$ & $87.97^{b}$ & $3.51^{b}$ & $8.52^{b}$ \\
\hline $1000 \mathrm{mg} / \mathrm{kg}$ diet & $53.35^{a}$ & $51.83^{a}$ & 2.84 & $87.40^{\mathrm{a}}$ & $90.84^{a}$ & $3.70^{\mathrm{b}}$ & $5.46^{d}$ \\
\hline $1500 \mathrm{mg} / \mathrm{kg}$ diet & $52.62^{b}$ & $51.30^{\mathrm{ab}}$ & 2.50 & $84.60^{a}$ & $88.51^{b}$ & $4.15^{\mathrm{ab}}$ & $7.34^{c}$ \\
\hline SEM & 0.16 & 0.22 & 0.27 & 1.10 & 0.24 & 0.31 & 0.34 \\
\hline \multicolumn{8}{|l|}{ Probability } \\
\hline IT & 1.0000 & 0.1812 & 0.0407 & 0.0362 & 0.0001 & 0.0905 & 0.0393 \\
\hline $\mathrm{BP}$ & 0.0032 & 0.0363 & 0.7330 & 0.0041 & 0.0001 & 0.0362 & 0.0001 \\
\hline interaction (IT × BP) & 1.0000 & 0.9729 & 0.9013 & 0.0289 & 0.0001 & 0.0041 & 0.0073 \\
\hline
\end{tabular}

EW - egg weight; EW-8d - egg weight at day 8; RWL - relative water loss; HSE - hatchability of set egg; HFE - hatchability of fertile eggs; DAP - dead after piping; EM - embryonic mortality; SEM - standard error of mean; ${ }^{\text {abc }}$ - means within the same column (separately for IT and BP effect) with different superscripts are significantly different at $P \leq 0.05$ 
Table 2. Effect of egg incubation temperature and bee pollen treatment of hens on chick quality traits and internal organ percentages

\begin{tabular}{|c|c|c|c|c|c|c|c|}
\hline \multirow{2}{*}{ Indices } & \multicolumn{3}{|c|}{ Chick quality traits } & \multicolumn{4}{|c|}{ Internal organ percentages } \\
\hline & ChW, g & RChW, \% & $\mathrm{ChL}, \mathrm{cm}$ & DSW, \% & spleen, \% & liver, \% & heart, \% \\
\hline \multicolumn{8}{|c|}{ Effect of incubation temperature (IT) } \\
\hline chronic $\left(40^{\circ} \mathrm{C}\right)$ & 37.12 & 70.39 & 15.84 & 11.87 & $0.094^{a}$ & $2.07^{b}$ & $0.47^{\mathrm{b}}$ \\
\hline normal $\left(37.8^{\circ} \mathrm{C}\right)$ & 37.46 & 71.03 & 15.97 & 10.92 & $0.055^{b}$ & $2.34^{a}$ & $0.60^{\mathrm{a}}$ \\
\hline SEM & 0.262 & 0.567 & 0.117 & 0.47 & 0.008 & 0.05 & 0.01 \\
\hline \multicolumn{8}{|c|}{ Effect of bee pollen treatments (BP) } \\
\hline control & 36.89 & 70.53 & 15.57 & 10.74 & 0.065 & $2.13^{\mathrm{bc}}$ & $0.508^{b}$ \\
\hline $500 \mathrm{mg} / \mathrm{kg}$ diet & 37.14 & 70.51 & 16.08 & 11.79 & 0.073 & $2.28^{a b}$ & $0.583^{a}$ \\
\hline 1000 mg/kg diet & 37.33 & 69.97 & 16.03 & 11.22 & 0.068 & $2.38^{a}$ & $0.519^{b}$ \\
\hline $1500 \mathrm{mg} / \mathrm{kg}$ diet & 37.79 & 71.82 & 15.93 & 11.83 & 0.093 & $2.01^{c}$ & $0.532^{b}$ \\
\hline SEM & 0.37 & 0.80 & 0.17 & 0.66 & 0.01 & 0.07 & 0.013 \\
\hline \multicolumn{8}{|l|}{ Probability } \\
\hline IT & 0.3692 & 0.4318 & 0.4630 & 0.1719 & 0.0048 & 0.0016 & 0.0001 \\
\hline $\mathrm{BP}$ & 0.4004 & 0.4339 & 0.1588 & 0.6134 & 0.3709 & 0.0099 & 0.0070 \\
\hline interaction $(\mathrm{IT} \times \mathrm{BP})$ & 0.2153 & 0.3124 & 0.0509 & 0.2330 & 0.5442 & 0.0166 & 0.0008 \\
\hline
\end{tabular}

ChW - chick weight; RChW - relative chick weight; ChL - chick length; DSW - digestive system weight; SEM - standard error of mean; abc - means within the same column (separately for IT and BP effect) with different superscripts are significantly different at $P \leq 0.05$

than in the normal $\left(37.5^{\circ} \mathrm{C}\right)$ group. These results agree with those of Maatjens et al. (2014) who showed that the development of liver and intestine is suppressed in chick embryos exposed to higher incubation temperatures. The same was achieved by Leksrisompong et al. (2007) who found that the heart weights of broilers produced from eggs exposed to higher eggshell temperatures $\left(39.5^{\circ} \mathrm{C}\right)$ after 14 days of incubation significantly decreased by about $17-31 \%$, which may contribute to metabolic disorders of liver associated with the development of cardiovascular problems such as ascites (Molenaar et al., 2011).

In chicks produced from hens administered with BP, the ChW, RchW, ChL, DSW and spleen (\%) were not affected, while liver and heart percentages were significantly $(P \leq 0.05)$ affected in comparison to the control group. This could be attributed to the role of BP in the reduction of adverse effects of high incubation temperature. These results agree with Aygun (2016) who stated that the chick body weight at hatching was not affected by the in ovo injection of 1,2 and 3\% propolis during the incubation period.

There were no significant effects of thermal stress and BP treatment interaction on chick weight, RChW, DSW and spleen (\%), while ChL, liver, and heart percentages were significantly $(P \leq 0.05)$ affected.

\section{Haematological parameters, leukocytes differential percentages in the chicks at hatch}

As it is presented in Table 3, RBCs $\left(\times 10^{6}\right), \mathrm{Hb}$ $(\mathrm{g} / \mathrm{dl})$ and PCV $(\%)$, WBCs $\left(\times 10^{3}\right), \mathrm{H}: \mathrm{L}$ ratio were significantly $(P \leq 0.05)$ affected by incubation manipulation, while monocytes and eosinophils were not affected. The reduction in the RBCs, $\mathrm{PCV}, \mathrm{Hb}$ and WBCs in the chronic group could be attributed to the adverse effects of high incubation temperature on the embryos. These results disagree with those of Ipek et al. (2015), who found that the higher PCV and RBC values were obtained in the high incubation group as compared to the low incubation temperature and control groups, while the $\mathrm{Hb}$ level was lower in the control group than in the high and low incubation temperature groups.

At hatching, the obtained results indicated that the heterophil percentages, as well as the H:L ratio, were higher, while the percentages of lymphocytes were lower in chicks produced from eggs exposed to high incubation temperature during early incubation period. These differences in the H:L ratio could be explained by the chick natural cellular immunity especially during the incubation period and consequently immediately at hatching. Also, the higher lymphocyte percentage could reflect the differences between the neonatal and adult periods of chick live. The heterophils have been considered 
Table 3. Effect of egg incubation temperature and bee pollen treatment of hens on haematological parameters of newly hatch chicks

\begin{tabular}{|c|c|c|c|c|c|c|c|c|c|}
\hline Indices & RBCs, $\times 10^{6}$ & $\mathrm{Hb}, \mathrm{g} / \mathrm{dl}$ & PCV, \% & WBCs, $\times 10^{3}$ & $\mathrm{H}, \%$ & $L, \%$ & $\mathrm{H}: \mathrm{L}$ ratio & $\mathrm{M}, \%$ & $E, \%$ \\
\hline \multicolumn{10}{|c|}{ Effect of incubation temperatures (IT) } \\
\hline chronic $\left(40^{\circ} \mathrm{C}\right)$ & $4.60^{\mathrm{b}}$ & $9.07^{b}$ & $27.25^{b}$ & $18.67^{\mathrm{b}}$ & $23.92^{\mathrm{a}}$ & $72.50^{\mathrm{b}}$ & $0.331^{\mathrm{a}}$ & 1.75 & 1.83 \\
\hline normal $\left(37.8^{\circ} \mathrm{C}\right)$ & $5.00^{\mathrm{a}}$ & $9.90^{\mathrm{a}}$ & $29.67^{a}$ & $20.42^{\mathrm{a}}$ & $20.17^{b}$ & $76.58^{\mathrm{a}}$ & $0.264^{b}$ & 1.50 & 1.75 \\
\hline SEM & 0.09 & 0.16 & 0.74 & 0.288 & 0.55 & 0.50 & 0.009 & 0.29 & 0.34 \\
\hline \multicolumn{10}{|c|}{ Effect of bee pollen treatments (BP) } \\
\hline control & $4.20^{\circ}$ & $8.28^{c}$ & $24.83^{c}$ & $17.00^{c}$ & $24.00^{\mathrm{a}}$ & $72.00^{b}$ & $0.339^{a}$ & 1.83 & 2.17 \\
\hline $500 \mathrm{mg} / \mathrm{kg}$ diet & $4.77^{\mathrm{b}}$ & $9.43^{b}$ & $28.17^{b}$ & $18.50^{b}$ & $21.17^{b}$ & $75.50^{\mathrm{a}}$ & $0.280^{b}$ & 1.50 & 1.83 \\
\hline $1000 \mathrm{mg} / \mathrm{kg}$ diet & $5.58^{\mathrm{a}}$ & $10.98^{\mathrm{a}}$ & $33.33^{a}$ & $21.17^{\mathrm{a}}$ & $21.00^{b}$ & $75.67^{\mathrm{a}}$ & $0.278^{b}$ & 1.67 & 1.67 \\
\hline $1500 \mathrm{mg} / \mathrm{kg}$ diet & $4.65^{b}$ & $9.28^{b}$ & $27.50^{\mathrm{b}}$ & $21.50^{\mathrm{a}}$ & $22.00^{\mathrm{ab}}$ & $75.00^{\mathrm{a}}$ & $0.294^{b}$ & 1.50 & 1.50 \\
\hline SEM & 0.13 & 0.23 & 1.05 & 0.41 & 0.79 & 0.71 & 0.01 & 0.42 & 0.48 \\
\hline \multicolumn{10}{|l|}{ Probability } \\
\hline IT & 0.0001 & 0.0027 & 0.0358 & 0.0006 & 0.0002 & 0.0069 & 0.0001 & 0.5569 & 0.8640 \\
\hline $\mathrm{BP}$ & 0.0070 & 0.0001 & 0.0003 & 0.0001 & 0.0580 & 0.0001 & 0.0144 & 0.9303 & 0.7872 \\
\hline interaction $(\mathrm{IT} \times \mathrm{BP})$ & 0.0001 & 0.0001 & 0.0012 & 0.0001 & 0.0395 & 0.0055 & 0.0113 & 0.5770 & 0.6268 \\
\hline
\end{tabular}

RBCs - red blood cells; Hb - haemoglobin; PCV - packed cell volume; WBCs - white blood cells; H - heterophils; L - lymphocytes; M monocytes; E - eosinophils; SEM - standard error of mean; abc - means within the same column (separately for IT and BP effect) with different superscripts are significantly different at $P \leq 0.05$

as the response to heat stress in chicks (Maxwell et al., 1992), while the H:L ratio was used as an index to measure the stress in birds (Gross and Siegel, 1983).

Haematological parameters such as RBCs, $\mathrm{Hb}$, PCV, WBCs, lymphocytes, heterophils and H:L ratio were significantly affected $(P \leq 0.05)$, while monocytes and eosinophils were not affected by the BP treatment. The mean of WBCs significantly increased in the treated groups when compared with control group. This could be attributed to increasing immunity efficiency of newly hatched chicks. The increased $\mathrm{Hb}$ content and PCV percentage in all groups treated with BP could be explained by the role which BP plays in protecting the membrane integrity of RBC as well as the role of it in increasing the iron level and consequently the absorption of the iron from the digestive tract. The increased $\mathrm{Hb}$ concentration in the blood the increased iron absorption from the digestive tract is found. The obtained findings agree with those of Adenkola et al. (2010) who noted that the values of PCV and $\mathrm{Hb}$ of birds treated with vitamin $\mathrm{C}$ significantly increased in comparison to those in untreated birds. The improved WBCs (\%) and $\mathrm{H}: \mathrm{L}$ ratio immune response in the newly chicks produced from eggs administered with BP may be due to the contents of minerals, antioxidant representing the flavonoids as well as vitamins in BP, which enhance immune system. These findings agree with those of Awad et al. (2013) who noted the higher lymphocyte percentages in hens administered with 1.0 and $1.5 \mathrm{~g}$ bee bread/ $\mathrm{kg}$ diet, while the heterophils and H:L ratio were significantly lower than in the control group.

All haematological parameters were significantly $(P \leq 0.05)$ affected by the interaction, except monocyte and eosinophil percentages.

\section{Thyroid hormone concentrations and cloacal temperature of newly hatched chicks}

At hatching it was shown a significant increase in plasma $\mathrm{T} 3$ and $\mathrm{T} 4$ hormone concentrations $(P<0.001)$ for eggs in the chronic group as compared to control one (Table 4). Such an increase in the thyroid hormones could reflect the role of these hormones in the regulation of heat production in the body. These results agree with those of Piestun et al. (2011) who reported that the T3 hormone concentration was significantly higher in chickens in the thermal manipulation group than in those from control one. This is in agreement with the results obtained by Abuoghaba (2017) where the highest values of T3 hormone for newly hatched chicks were found in the control, while the lowest one was recorded in the chronic group. Contrarily, the results of Badran et al. (2012) indicate that T3 levels in the chronic group were significantly lower as compared to control one throughout all embryonic stages. Also, the results of the present study showed that the cloacal temperature of the hatched chick in the chronic group significantly $(P \leq 0.05)$ increased in comparison to the control group. The increased cloacal temperature in the chronic temperature can indicate embryo response to high incubation temperature. These results 
Table 4. Effect of egg incubation temperature and bee pollen treatment of hens on the thyroid hormones concentration and cloacal temperature

\begin{tabular}{|c|c|c|c|}
\hline \multirow{2}{*}{ Indices } & \multicolumn{2}{|c|}{ Thyroid hormones } & \multirow{2}{*}{ Cloacal temperature, ${ }^{\circ} \mathrm{C}$} \\
\hline & $\mathrm{T} 3, \mathrm{ng} / \mathrm{dl}$ & $\mathrm{T} 4, \mu \mathrm{g} / \mathrm{dl}$ & \\
\hline \multicolumn{4}{|c|}{ Effect of incubation temperatures (IT) } \\
\hline chronic $\left(40^{\circ} \mathrm{C}\right)$ & $175.66^{\mathrm{a}}$ & $12.69^{a}$ & $38.53^{a}$ \\
\hline normal $\left(37.8^{\circ} \mathrm{C}\right)$ & $137.33^{b}$ & $10.23^{b}$ & $37.73^{b}$ \\
\hline SEM & 1.29 & 0.15 & 0.12 \\
\hline \multicolumn{4}{|c|}{ Effect of bee pollen treatments (BP) } \\
\hline control & $148.50^{\circ}$ & $11.08^{b}$ & 38.40 \\
\hline $500 \mathrm{mg} / \mathrm{kg}$ diet & $157.50^{\mathrm{b}}$ & $11.98^{\mathrm{a}}$ & 38.17 \\
\hline $1000 \mathrm{mg} / \mathrm{kg}$ diet & $166.17^{\mathrm{a}}$ & $12.45^{\mathrm{a}}$ & 38.05 \\
\hline $1500 \mathrm{mg} / \mathrm{kg}$ diet & $153.83^{\mathrm{bc}}$ & $10.33^{c}$ & 37.92 \\
\hline SEM & 1.82 & 0.21 & 0.26 \\
\hline \multicolumn{4}{|l|}{ Probability } \\
\hline IT & 0.0001 & 0.0001 & 0.0002 \\
\hline $\mathrm{BP}$ & 0.0001 & 0.0001 & 0.2464 \\
\hline Interaction (IT × BP) & 0.0001 & 0.0001 & 0.8233 \\
\hline
\end{tabular}

T3 - triiodothyronine; T4 - thyroxin; SEM - standard error of mean; abc - means within the same column (separately for IT and BP effect) with different superscripts are significantly different at $P \leq 0.05$

confirm those of Ipek et al. (2015) who found that the cloacal temperature was significantly increased to $40.5{ }^{\circ} \mathrm{C}$ in chicks from the high incubation temperature group $\left(38.9-40.0^{\circ} \mathrm{C}\right)$ in comparison with low incubation temperature group $\left(33.3-36.7^{\circ} \mathrm{C}\right)$ and control one $\left(37.8-38.2^{\circ} \mathrm{C}\right)$, in which the cloacal temperature was 38.7 and $39.4{ }^{\circ} \mathrm{C}$, respectively.

Treating animals with 500 and $1000 \mathrm{mg} \mathrm{BP} / \mathrm{kg}$ diet significantly $(P \leq 0.05)$ increased T3 and T4 plasma concentrations; while in group treated with $1500 \mathrm{mg} / \mathrm{kg}$ diet T3 did not differ and T4 was significantly lower from the control group. The significant increase in T3 hormone concentration in newly hatched chicks could reflected positive effects of BP improved chick weight as well as physiological status in the treated groups. There was no effect of BP treatment on the cloacal temperature.

Both T3 and T4 were significantly influenced by the interaction between main effects, while no such relationship was stated for the cloacal temperature.

\section{Conclusions}

In the present study it is clearly shown that exposing hatching eggs to chronic temperature during the early incubation period negatively affected hatchability and chick performance. On the other hand, dietary treatment of hens with bee pollen (BP) improved many incubation and haematological traits, and the most preferable doses of BP were 500 and $1000 \mathrm{mg} \mathrm{BP} / \mathrm{kg}$ diet. Thus, it could be recommended to use BP in the hen diet to reduce the adverse effects of high incubation temperatures during the early incubation period, which may be important in high-temperature countries like Egypt.

\section{Acknowledgments}

This study was performed at El-Serw Poultry Research Station, Animal production Research Institute, Agricultural Research Center, Egypt.

\section{References}

Abuoghaba A.A., 2017. Impact of spraying incubated eggs submitted to high temperature with ascorbic acid on embryonic development, hatchability, and some physiological responses of hatched chicks. Can. J. Anim. Sci. 97, 172-182

Adenkola A.Y., Kaankuka F.G., Ikyume T.T., Ichaver I.F., Yaakugh I.D.I., 2010. Ascorbic acid effect on erythrocyte osmotic fragility, haematological parameters and performance of weaned rabbits at the end of rainy season in Makurdi, Nigeria. J. Anim. Plant Sci. 9, 1077-1085

Awad A.L., Beshara M.M., Ibrahim A.F., Fahim H.N., 2013. Effect of using bee bread as a natural supplement on productive and physiological performance of local Sinai hens. Egypt. Poult. Sci. 33, 889-913

Aygun A., 2016. The effects of in-ovo injection of propolis on egg hatchability and starter live performance of Japanese quails. Rev. Bras. Cienc. Avic. 18 (Spec. Issue 2), 83-89, https://doi. org/10.1590/1806-9061-2015-0198

Badran A.M., Desoky A., Abou-Eita E.M., Stino F.K., 2012. Epigenetic thermal adaptation of chickens during late embryonic development. Egypt. Poult. Sci. 32, 675-689

Carpes S.T., Begnini R., de Alencar S.M., Masson M.L., 2007. Study of preparations of bee pollen extracts, antioxidant and antibacterial activity. Cienc. Agrotec. 31, 1818-1825, https://doi. org/10.1590/S1413-70542007000600032 
Coşkun I., Çayan H., Yilmaz O., Taskin A., Tahtabıçen E., Samlı H.H., 2014. Effects of in ovo pollen extract injection to fertile broiler eggs on hatchability and subsequent chick weight. Turkish J. Agric. Nat. Sci. 1, 485-489

Darras V.M., Kotanen S.P., Geris K.L., Berghman L.R., Kühn E.R., 1996. Plasma thyroid hormone levels and iodothyronine deiodinase activity following an acute glucocorticoid challenge in embryonic compared with posthatch chickens. Gen. Comp. Endocrinol. 104, 203-212, https://doi.org/10.1006/ gcen.1996.0163

Duncan B.D., 1955. Multiple range and multiple F tests. Biometrics 11, 1-42, https://doi.org/10.2307/3001478

Farag S.A., El-Rayes T.K., 2016. Effect of bee-pollen supplementation on performance, carcass traits and blood parameters of broiler chickens. Asian J. Anim. Vet. Adv. 11, 168-177, https:// doi.org/10.3923/ajava.2016.168.177

Geng Z.Y., Wang X.L. 1990. Relationship of hatchability and the percentage of egg weight loss and shell pore concentration during incubation (in Chinese). Chin. J. Anim. Sci. 1990-05

Gross W.B., Siegel H.S., 1983. Evaluation of the heterophil/ lymphocyte ratio as a measure of stress in chickens. Avian Dis. 27, 972-979, https://doi.org/10.2307/1590198

Hill D., 2001. Chick length uniformity profiles as a field measurement of chick quality. Avian Poult. Biol. Rev. 12, 188 (Abstr.)

Hulet R.M., Gladys G., Hill D., Meijerhof R., El-Shiekh T., 2007. Influence of egg shell embryonic incubation temperature and broiler breeder flock age on posthatch growth performance and carcass characteristics. Poult. Sci. 86, 408-412, https:// doi.org/10.1093/ps/86.2.408

IpekA., Sahan U., Sozcu A., 2015. The effects of different eggshell temperatures between embryonic day 10 and 18 on broiler performance and susceptibility to ascites. Rev. Bras. Cienc. Avic. 17, 387-394, https://doi.org/10.1590/1516-635X1703387-394

Leksrisompong N., Romeo-Sanchez H., Plumstead P.W., Brannan K.E., Brake J., 2007. Broiler incubation. 1. Effect of elevated temperature during late incubation on body weight and organs of chicks. Poult. Sci. 86, 2685-2691, https://doi. org/10.3382/ps.2007-00170

Liu G., Yan W., Zeng Z., 2010. Application of bee pollen on the Gallus feed. J. Bee, 3, 8-9

Lourens A., van den Brand H., Meijerhof R., Kemp B., 2005. Effect of eggshell temperature during incubation on embryo development, hatchability, and posthatch development. Poult. Sci. 84, 914-920, https://doi.org/10.1093/ps/84.6.914

Maatjens C.M., Reijink I.A.M., Molenaar R., van der Pol C.W., Kemp B., van den Brand H., 2014. Temperature and CO2 during the hatching phase. I. Effects on chick quality and organ development. Poult. Sci. 93, 645-654, https://doi. org/10.3382/ps.2013-03490
Maxwell M.H., Robertson G.W., Mitchell M.A., Carlisle A.J., 1992. The fine structure of broiler chicken blood cells, with particular reference to basophils, after severe heat stress. Comp. Haematol. Int. 2, 190-200, https://doi.org/10.1007/BF00216094

Molenaar R., Hulet R., Meijerhof R., Maatjens C.M., Kemp B., van den Brand, 2011. High eggshell temperatures during incubation decrease growth performance and increase the incidence of ascites in broiler chickens. Poult. Sci. 90, 624-632, https://doi. org/10.3382/ps.2010-00970

Narinç D., Erdoğan S., Tahtabiçen E., Aksoy T., 2016. Effects of thermal manipulations during embryogenesis of broiler chickens on developmental stability, hatchability and chick quality. Animal 10, 1328-1335, https://doi.org/10.1017/S1751731116000276

Piestun Y., Halevy O., Shinder D., Ruzal M., Druyan S., Yahav S., 2011. Thermal manipulations during broiler embryogenesis improves post-hatch performance under hot conditions. J. Therm. Biol. 36, 469-474, https://doi.org/10.1016/j.jtherbio.2011.08.003

Schalm O.W., Jain N.C., Caroll E.J., 1975. Veterinary Hematology. $3^{\text {rd }}$ Edition. Lea \& Febiger Publication. Philadelphia, PA (USA), pp. 15-81

Sgavioli S., Matos Júnior J.B., Borges L.L., Praes M.F.F.M., Morita V.S., Zanirato G.L., Garcia R.G., Boleli I.C., 2015. Effects of ascorbic acid injection in incubated eggs submitted to heat stress on incubation parameters and chick quality. Rev. Bras. Cienc. Avic. 17, 181-190, https://doi.org/10.1590/1516$635 \times 1702181-190$

Shen P.F., Patterson L.T., 1983. A simplified wright's stain technique for routine avain blood smear staining. Poult. Sci. 62, 923-924, https://doi.org/10.3382/ps.0620923

Song Y.-f., Wang J., Li S.-h., Shang C.-f., 2005. Effect of bee pollen on the development of digestive gland of broilers. Anim. Husb. Vet. Med. 2005-04

Willemsen H., Kamers B., Dahlke F., Han H., Song Z., Ansari Pirsaraei Z., Tona K., Decuypere E., Everaert N., 2010. Highand low-temperature manipulation during late incubation: Effects on embryonic development, the hatching process, and metabolism in broiler. Poult. Sci. 89, 2678-2690, https://doi. org/10.3382/ps.2010-00853

Wilson H.R., 1991. Physiological requirements of the developing embryo: temperature and turning. In: S.G. Tullet (Editor). Avian Incubation. Butterworth-Heinemann. London (UK), pp, 145-156

Yahav S., Collin A., Shinder D., Picard M., 2004. Thermal manipulations during broiler chick embryogenesis: effects of timing and temperature. Poult. Sci. 83, 1959-1963, https://doi. org/10.1093/ps/83.12.1959 